\title{
Acknowledgements
}

Even a solo project is a collaborative effort. I am grateful to many people who helped bring this book into being.

To my editors, Matthew, Diana and Robert, for their expertise, professionalism and confidence.

To my readers and mentors, Natalie, Leslie B., Ben, Andrew, Michael, Leslie K. and Thibaut, for their advice, generosity and overall brilliance.

To my students, whose discussions of these films inspired and motivated me.

To my colleagues at the Australian National University, who supported me in many ways to do this research, and at Paris Sciences et Lettres, who gave me resources and community so I could write in Paris.

To my family, friends and partner, Sam, for their love, wisdom and willingness to stretch their tolerance for screen violence in order to watch these films with me.

And to Jacques Audiard, for meeting with me, and for making films that have beguiled me ever since I was a brighteyed undergraduate who enrolled, on a whim, in a unit called 'French Cinema: The New Wave and Beyond'.

\section{Note on translations}

Unless otherwise stated, all French quotes in this book have been translated into English by me. 